\title{
LEAKAGE AND SEEPAGE IN THE NEAR-SURFACE ENVIRONMENT: AN INTEGRATED APPROACH TO MONITORING AND DETECTION
}

\author{
Curtis M. Oldenburg and Jennifer L. Lewicki \\ Earth Sciences Division 90-1116, LBNL, Berkeley CA 94720
}

\begin{abstract}
Monitoring and detection of leakage and seepage of carbon dioxide $\left(\mathrm{CO}_{2}\right)$ in the near-surface environment is needed to ensure the safety and effectiveness of geologic carbon sequestration. Large leakage fluxes, e.g., through leaking wells, will be easier to detect and monitor than slow and diffuse leakage and seepage. The challenge of detecting slow leakage and seepage is discerning a leakage or seepage signal from within the natural background variations in $\mathrm{CO}_{2}$ concentration and flux that are controlled by a variety of coupled processes in soil. Although there are no direct examples of leaking geologic carbon sequestration sites on which to base a proposed verification approach, we have been guided by our prior simulation studies of $\mathrm{CO}_{2}$ leakage and seepage, which showed that large $\mathrm{CO}_{2}$ concentrations can develop in the shallow subsurface even for relatively small $\mathrm{CO}_{2}$ leakage fluxes. A variety of monitoring technologies exists for measuring $\mathrm{CO}_{2}$ concentration and flux, but there is a gap between instrument performance and the detection of a leakage or seepage signal from within large natural background variability. We propose an integrated approach to monitoring and verification. The first part of our proposed approach is to characterize and understand the natural ecosystem before $\mathrm{CO}_{2}$ injection occurs so that future anomalies can be recognized. Measurements of natural $\mathrm{CO}_{2}$ fluxes using accumulation chamber (AC) and eddy correlation (EC) approaches, soil $\mathrm{CO}_{2}$ concentration profiles with depth, and carbon isotope compositions of $\mathrm{CO}_{2}$ are needed to characterize the natural state of the system prior to $\mathrm{CO}_{2}$ injection. From this information, modeling needs to be carried out to enhance understanding of carbon sources and sinks so that anomalies can be recognized and subject to closer scrutiny as potential leakage or seepage signals. Long-term monitoring using AC, EC, and soil-gas analyses along with ecosystem and flow and transport modeling should continue after $\mathrm{CO}_{2}$ injection. The integrated use of multiple measurements and modeling offers a promising approach to discerning and quantifying a small $\mathrm{CO}_{2}$ leakage or seepage signal from within the expected background variability.
\end{abstract}

\section{Introduction}

One of the outstanding challenges of geologic carbon sequestration is verification, that is, ensuring that carbon dioxide $\left(\mathrm{CO}_{2}\right)$ is not leaking from the intended sequestration formation and seeping out of the ground. The most straightforward way of verifying $\mathrm{CO}_{2}$ sequestration would seem to be direct monitoring and detection of anomalous $\mathrm{CO}_{2}$ in the near-surface environment. While catastrophic releases to the atmosphere, such as through well blowouts, will be obvious failures and therefore present no challenge for detection, slow or diffuse leakage and seepage of $\mathrm{CO}_{2}$ will be much more difficult to detect, monitor, and quantify. The difficulty of observing and quantifying diffuse $\mathrm{CO}_{2}$ leakage and seepage arises because there are large spatial and temporal changes in $\mathrm{CO}_{2}$ concentration and flux in natural ecosystems, making the main challenge the detection of a $\mathrm{CO}_{2}$ leakage or seepage signal from within the natural background variation. We have developed an approach for monitoring and verification that involves a variety of integrated measurements and modeling that could be used to discern a $\mathrm{CO}_{2}$ leakage or seepage signal.

In this brief paper, we summarize our proposed approach for geologic carbon sequestration verification. This approach is guided by results of numerical simulations of $\mathrm{CO}_{2}$ leakage and seepage that we have carried out over the last few years, and by our experience in monitoring natural systems. Next we review controls on natural $\mathrm{CO}_{2}$ in the shallow subsurface, and the technologies used for detecting and monitoring $\mathrm{CO}_{2}$ in the near-surface environment. Finally, we present our ideas for an integrated approach to $\mathrm{CO}_{2}$ verification.

\footnotetext{
*Corresponding author: Tel. (510) 486-7419, Fax. (510) 486-5686, Email: cmoldenburg@lbl.gov
} 


\section{Review of Simulated $\mathrm{CO}_{2}$ Leakage and Seepage}

In prior work, we carried out simulations of $\mathrm{CO}_{2}$ leakage and seepage using T2CA, a recently developed extension of TOUGH2 [1] that models $\mathrm{CO}_{2}$ migration and dispersion in the subsurface and atmospheric surface layer. Details of the methods used in T2CA can be found in Oldenburg and Unger [2,3]. Numerical simulations showed that $\mathrm{CO}_{2}$ concentrations can build up to high levels in the vadose zone $\left(\sim 100 \% \mathrm{CO}_{2}\right.$ in soil gas $)$ even when the leakage occurs at a relatively small rate. The reason for this is that there are very few dissipative processes for leaking $\mathrm{CO}_{2}$ in the vadose zone. Examples of dissipative processes are dissolution of $\mathrm{CO}_{2}$ into vadose zone

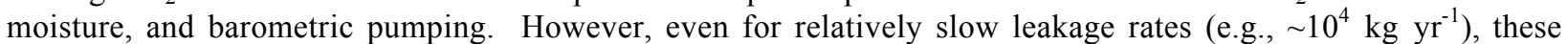
processes do not significantly attenuate $\mathrm{CO}_{2}$ leakage in the vadose zone [2]. Although the shallow subsurface $\mathrm{CO}_{2}$ concentrations can be high, the $\mathrm{CO}_{2}$ seepage flux across the ground surface can be small as $\mathrm{CO}_{2}$ emissions occur over a large area. Our simulation results for the atmospheric surface layer show that $\mathrm{CO}_{2}$ concentrations are very low above the ground surface, due to wind and turbulence which dilute and disperse $\mathrm{CO}_{2}$ [3]. As wind speed increases, the surface-layer concentrations diminish to small values above the background concentration of 370 ppmv [3]. These observations of the expected behavior of leaking and seeping $\mathrm{CO}_{2}$ have led us to focus monitoring and verification on the shallow subsurface, where $\mathrm{CO}_{2}$ concentrations will tend to be high, and the daily and seasonal variability will be diminished relative to the above-ground region.

\section{Natural Background $\mathrm{CO}_{2}$ Fluxes and Concentrations}

Background $\mathrm{CO}_{2}$ in soil is derived primarily from the atmosphere and respiration, i.e., biologically mediated oxidation of organic carbon. A diagram of soil $\mathrm{CO}_{2}$ sources and exchanges is shown in Figure 1. As shown in Figure 1, background soil $\mathrm{CO}_{2}$ fluxes and concentrations are dependent on exchange with the atmosphere, production from decay of organic matter such as leaf litter, uptake by plants, production by root respiration, deep degassing, release from groundwater due to depressurization, and production by oxidation of organic carbon in groundwater at the water table. These processes are dependent on temperature, moisture, soil aeration, biological activity, and other factors [4]. The $\mathrm{CO}_{2}$ degassed by flowing deep groundwater can have its $\mathrm{CO}_{2}$ source from shallower sources (e.g., respiration, atmospheric $\mathrm{CO}_{2}$, or particulate organic carbon) encountered at shallower depths over the long groundwater migration pathway (e.g., [5]). In summary, many complex and interrelated processes are active in controlling the natural background variation of $\mathrm{CO}_{2}$ concentration, flux, and isotopic composition, and these processes can vary on short (hourly) and much longer time scales.

\section{Near-Surface Monitoring Technologies}

A wide range of methods is available for monitoring and detection of $\mathrm{CO}_{2}$ fluxes and concentrations [6,7]. The infrared gas analyzer (IRGA) is used to measure $\mathrm{CO}_{2}$ concentrations and is based on the principle of light absorption in the near-infrared part of the spectrum, typically $4.26 \mu \mathrm{m}$. IRGA-based devices are inexpensive, portable, and can measure $\mathrm{CO}_{2}$ over a wide range of concentrations. Promising new methods of $\mathrm{CO}_{2}$ monitoring include light detection and range finding (LIDAR), and new approaches such as hyperspectral imaging of vegetative stress [8].

Two basic approaches exist for measuring $\mathrm{CO}_{2}$ fluxes: (1) the accumulation chamber (AC), and (2) the eddy correlation (EC) approach. In the AC method, an open-bottomed chamber is placed directly on the soil surface or on a collar installed on the ground surface and the rate of soil- $\mathrm{CO}_{2}$ accumulation is measured using an IRGA (Figure 2a). This approach provides a small-scale measurement of soil- $\mathrm{CO}_{2}$ flux. The measurement is relatively quick and many such measurements can be made over a large area, with statistical approaches used to interpolate an overall aereal flux [7]. The EC method provides a spatially averaged flux by correlating $\mathrm{CO}_{2}$ concentration measured at a fixed height above the ground using an IRGA with local meteorological variations at the same elevation (Figure 2b). After time-averaging of the local variations of concentration and vertical wind speed, an average flux over a given footprint is derived. The footprint area is a function of the instrument height above the ground surface and local wind velocity, and is on the order of 10-100 times the instrument height. The advantage of EC is that it provides a spatially averaged flux that includes plant and soil sources; the limitation is that it assumes a horizontal ground surface and uniform plant cover over the footprint [9]. 


\section{Proposed Integrated Approach to Sequestration Verification}

There is a wide gap between the performance capabilities of technological devices and their applicability for geologic carbon sequestration leakage or seepage monitoring, detection, and verification. The fundamental challenge for verification when leakage and seepage fluxes are small is discerning the $\mathrm{CO}_{2}$ leakage or seepage signal from natural background variability. Because $\mathrm{CO}_{2}$ leakage and seepage at the ground surface is expected be a very rare phenomenon, monitoring at $\mathrm{CO}_{2}$ sequestration sites will typically record background natural variability of the ecological system. To meet the challenge of $\mathrm{CO}_{2}$ sequestration verification, sophisticated procedures or new technologies may have to be developed. In this section, we discuss ways that the $\mathrm{CO}_{2}$ leakage or seepage signal could be discerned and quantified from measurements made in the near-surface environment with existing conventional devices.

The approach we suggest is based on our experience in modeling and field measurements of $\mathrm{CO}_{2}$ emissions $[2,3,10]$. Experience has shown that the subsurface, even at depths of less than a meter, is much less affected by surface environmental processes and the strong dispersion effects of surface-layer winds and barometric pressure changes. Therefore, we expect the changes in $\mathrm{CO}_{2}$ concentration, flux, and isotopic composition to be most recognizable in the subsurface, and therefore we focus our attention on monitoring and detection in the shallow subsurface. A great deal of effort should be put into understanding the natural ecological system and its baseline properties prior to $\mathrm{CO}_{2}$ injection so that future anomalies in $\mathrm{CO}_{2}$ concentration and flux can be identified. Particular attention should be given to understanding the natural variability in areas where leakage or seepage may be expected, e.g., near faults or around wells. Modeling and analyses of expected ecological (e.g., [11]) and $\mathrm{CO}_{2}$ transport dynamics (e.g., [1,2,3]) should be integrated with the measurements to develop a comprehensive understanding of the system with and without $\mathrm{CO}_{2}$ leakage and seepage.

We propose a variety of measurements for $\mathrm{CO}_{2}$ sequestration verification. First, bulk soil-gas composition can be analyzed as a function of depth (i.e., vertical soil-gas profiles). Increasing $\mathrm{CO}_{2}$ concentrations with depth indicate a $\mathrm{CO}_{2}$ source at depth. If the source is oxidative decay of organic matter, there should be an associated decrease in $\mathrm{O}_{2}$ concentration, the absense of which may suggest a $\mathrm{CO}_{2}$ leakage source. A more definitive way of distinguishing the source of carbon in $\mathrm{CO}_{2}$ in soil is by isotopic analyses. The characteristic properties of gas composition profiles and isotopic signatures for different sources of $\mathrm{CO}_{2}$ are summarized in Table 1 . Both the stable ${ }^{13} \mathrm{C}$ and radiogenic ${ }^{14} \mathrm{C}$ vary depending on the source of $\mathrm{CO}_{2}$. However, only the absence of ${ }^{14} \mathrm{C}$ coupled with high local $\mathrm{CO}_{2}$ concentrations provide a strong indicator of a fossil-fuel origin of $\mathrm{CO}_{2}$ consistent with leaking $\mathrm{CO}_{2}$ from a sequestration site. The overlap in ${ }^{13} \mathrm{C}$ values from the various potential sources of $\mathrm{CO}_{2}$ makes ${ }^{13} \mathrm{C}$ less useful as a leakage indicator. A large number of measurement locations will be required and statistical approaches will have to be used to interpolate relatively sparse measurements over the area of interest. In addition to measurements of gas composition and variation with depth, seepage flux should be measured using either AC or EC approaches. Areas of anomalous emissions would be obvious places to focus additional sampling and monitoring efforts. Measurements of gas components other than $\mathrm{CO}_{2}$ associated with the $\mathrm{CO}_{2}$ sequestration target, e.g., $\mathrm{CH}_{4}$ if the sequestration target formation is a hydrocarbon reservoir, may also be a promising indicator of potential leakage [12].

Integrated with both the baseline (i.e., pre-injection) characterization measurements and the ongoing monitoring should be numerical simulation [1,2,3] and ecological modeling [e.g., 11]. These analysis efforts should both make use of the measured observations (e.g., as calibration data) as well as make predictions that can be compared against the measurements, with disparities becoming the focus of particular scrutiny as potential leakage or seepage signals. In Figure 4, we present a proposed schedule of integrated monitoring and modeling activities for verification. We emphasize the need for pre-injection activities along with long-term monitoring during and after injection.

\section{Conclusions}

Verification of geologic carbon sequestration by monitoring and modeling in the near-surface environment is a challenging but necessary task to ensure the safety and effectiveness of geologic carbon sequestration. The challenge arises because of the large natural background variability in $\mathrm{CO}_{2}$ concentration and flux. We propose an approach that integrates several different measurements with modeling and analysis. Discrepancies between 
measurements and model results should be analyzed closely as they may point to evidence of $\mathrm{CO}_{2}$ leakage or seepage.

\section{Acknowledgments}

We thank xxx and xxx for reviews of an earlier draft. This work was supported in part by the Office of Science, U.S. Department of Energy, and by the Assistant Secretary for Fossil Energy, Office of Coal and Power Systems, through the National Energy Technologies Laboratory (NETL), and by Lawrence Berkeley National Laboratory under Department of Energy Contract No. DE-AC03-76SF00098.

\section{References}

1. Pruess, K., C. Oldenburg, and G. Moridis. 1999. TOUGH2 User's Guide Version 2.0, Lawrence Berkeley National Laboratory Report $L B N L-43134,197$ pp.

2. Oldenburg, C.M., and A.J.A. Unger. 2003. On leakage and seepage from geologic carbon sequestration sites: unsaturated zone attenuation, Vadose Zone Journal, 2, 287-296.

3. Oldenburg, C.M., and A.J.A. Unger. 2004. Coupled vadose zone and atmospheric surface-layer transport of $\mathrm{CO}_{2}$ from geologic carbon sequestration sites, Vadose Zone Journal, in press.

4. Amundson, R.G., O.A. Chadwick, and J.M. Sowers. 1989. A comparison of soil climate and biological activity along an elevation gradient in the eastern Mojave Desert, Oecologia, 80, 395-400.

5. Wood, W.W. and M.J. Petraitis. 1984. Origin and distribution of carbon dioxide in the unsaturated zone of the southern high plains of Texas, Water Resour. Res., 20, 1193-1208.

6. Shuler, P.J. and Y. Tang. 2002. Atmospheric $\mathrm{CO}_{2}$ Monitoring Systems - A Critical Review of Available Techniques and Technology Gaps: Report for SMV Group, The $\mathrm{CO}_{2}$ Capture Project (CCP).

7. Oldenburg, C.M., and J.L. Lewicki. 2003. Near-Surface Monitoring Strategies for Geologic Carbon Dioxide Storage Verification, Lawrence Berkeley National Laboratory Report LBNL-54089.

8. Martini, B.A., D.C. Potts, E.A. Silver and W.L. Pickles. 2000. Hypersprectral remote sensing for research and monitoring in active volcanic regions: Long Valley Caldera, CA, EOS Trans. Am. Geophys. Union, Fall Meeting, p. F1385.

9. Baldocchi, D.D., R. Valentini, S. Running, W. Oechel, and R. Dahlman. 1996. Strategies for measuring and modeling carbon dioxide and water vapor fluxes over terrestrial ecosystems, Global Change Biology, 2, $159-168$.

10. Lewicki, J.L., W.C. Evans, G.E. Hilley, M.L. Sorey, J.D. Rogie, and S.L. Brantley. 2003. Shallow soil CO 2 flow along the San Andreas and Calaveras faults, California, J. Geophys. Res., 108, ECV 3-1 - ECV 3-14.

11. Bonan, G.B.. 1996. A land surface model (LSM version 1.0) for ecological, hydrological, and atmospheric studies: Technical description and user's guide, $T N-417+S T R$, NCAR, Boulder, CO.

12. Klusman, R.W.. 2003. Evaluation of leakage potential from a carbon dioxide EOR/sequestration project, Energy Conversion and Management, 44, 1921-1940. 
Table 1. Chemical and isotopic signatures related to $\mathrm{CO}_{2}$ derived from different sources.

\begin{tabular}{|c|c|c|c|c|c|}
\hline $\mathrm{CO}_{2}$ source & $\begin{array}{c}\delta^{13} \mathrm{C}_{\mathrm{CO} 2} \\
\% \%\end{array}$ & $\begin{array}{c}\Delta^{14} \mathrm{C}_{\mathrm{CO} 2} \\
\% \text { \% }\end{array}$ & $\begin{array}{l}\text { Near-surface } \\
\mathrm{CO}_{2} \text { conc. }\end{array}$ & $\begin{array}{l}\mathrm{CO}_{2} \text { conc. depth } \\
\text { profile }\end{array}$ & $\begin{array}{l}\mathrm{O}_{2} \text { conc. depth } \\
\text { profile }\end{array}$ \\
\hline Atmosphere & -7 & -70 & Low & - & - \\
\hline $\begin{array}{l}\text { Plant root respiration } \\
\text { and oxidative decay } \\
\text { of young soil organic } \\
\text { matter }\end{array}$ & $\begin{array}{l}C_{3}:-24 \text { to }-38 \\
C_{4}:-6 \text { to }-19\end{array}$ & $\geq-70$ & $\begin{array}{l}\text { Low to } \\
\text { moderate }\end{array}$ & $\begin{array}{l}\text { Increasing through } \\
\text { soil zone }\end{array}$ & $\begin{array}{l}\text { Decreasing through } \\
\text { soil zone }\end{array}$ \\
\hline $\begin{array}{l}\text { Oxidative decay of } \\
\text { ancient organic } \\
\text { matter }\end{array}$ & $\begin{array}{c}\mathrm{C}_{3}:-24 \text { to }-38 \\
\text { Aquatic/ } \mathrm{C}_{4}: \\
-6 \text { to }-19 \\
\text { Also age } \\
\text { dependent }\end{array}$ & $\begin{array}{l}\text { Highly } \\
\text { depleted to } \\
\text { absent, } \\
\text { depending } \\
\text { on age }\end{array}$ & Low & $\begin{array}{l}\text { Increasing } \\
\text { potentially through } \\
\text { vadose zone }\end{array}$ & $\begin{array}{l}\text { Decreasing } \\
\text { potentially through } \\
\text { vadose zone }\end{array}$ \\
\hline $\begin{array}{l}\text { Marine carbonate } \\
\text { rocks }\end{array}$ & $0 \pm 4$ & absent & Low & $\begin{array}{l}\text { Increasing through } \\
\text { vadose zone }\end{array}$ & No effect \\
\hline Fossil fuel & Average: -27 & absent & $\begin{array}{l}\text { Moderate to } \\
\text { high }\end{array}$ & $\begin{array}{l}\text { Increasing through } \\
\text { vadose zone }\end{array}$ & No effect \\
\hline
\end{tabular}

Conc., $\mathrm{C}_{3}$, and $\mathrm{C}_{4}$, refer to concentration, $\mathrm{C}_{3}$ plants, and $\mathrm{C}_{4}$ plants. All near-surface concentrations given are general estimates; these concentrations will be strongly dependent on the magnitude of the $\mathrm{CO}_{2}$ flux.

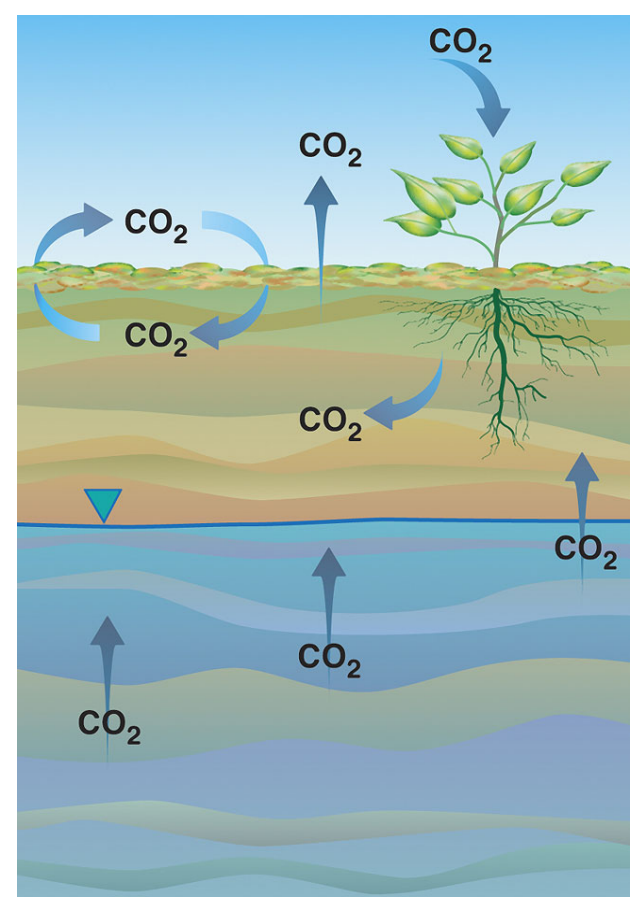

Figure 1. Soil $\mathrm{CO}_{2}$ sources and sinks, showing from left-right, top-bottom, exchange with the atmosphere, production from decay of organic matter such as leaf litter, uptake by plants, production by root respiration, deep degassing, release from groundwater due to depressurization, and production by oxidation of organic carbon in groundwater at the water table. 


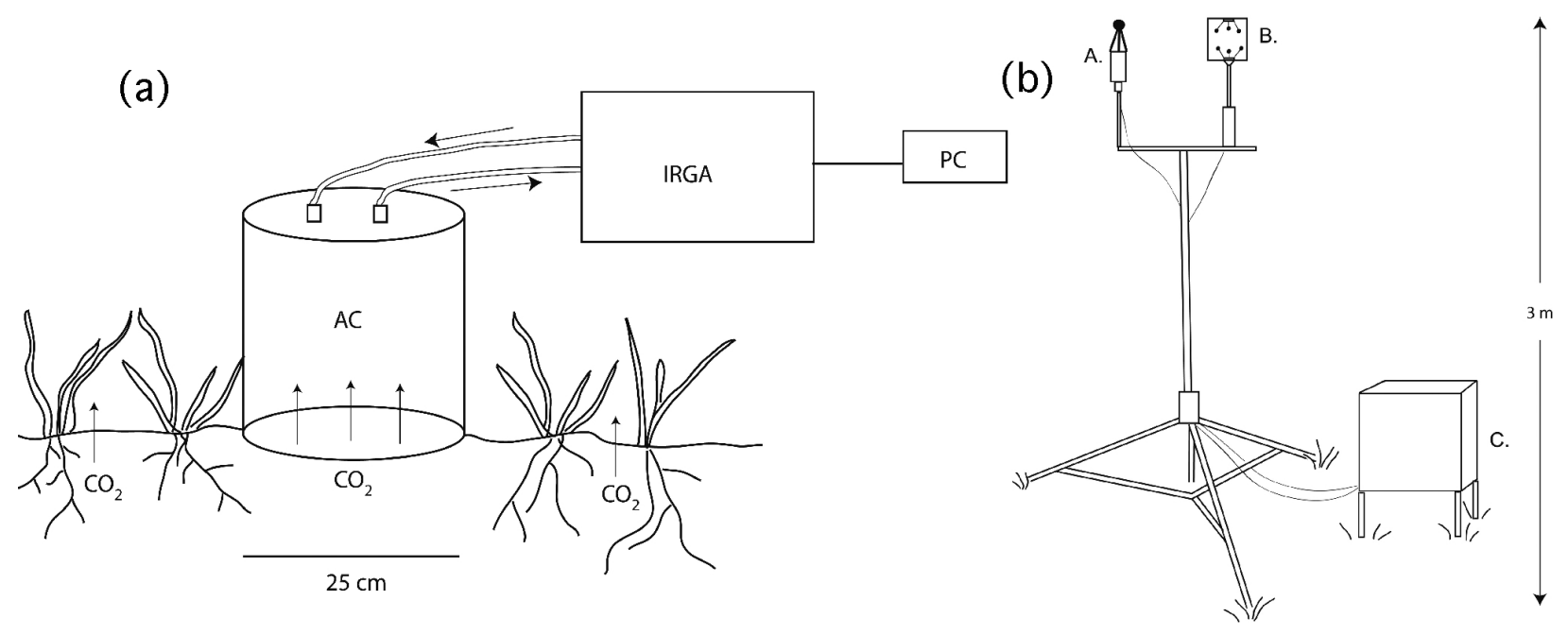

Figure 2. Sketch of (a) accumulation chamber (AC) measurement system of soil $\mathrm{CO}_{2}$ flux in which contained air is circulated through the $\mathrm{AC}$ and the IRGA and the rate of change of $\mathrm{CO}_{2}$ concentration in the $\mathrm{AC}$ is measured by the IRGA and recorded by the PC, and (b) eddy correlation (EC) instrumentation tower showing (A) open-path IRGA, (B) high frequency response sonic anemometer, and (C) box containing power source and datalogger/PC.

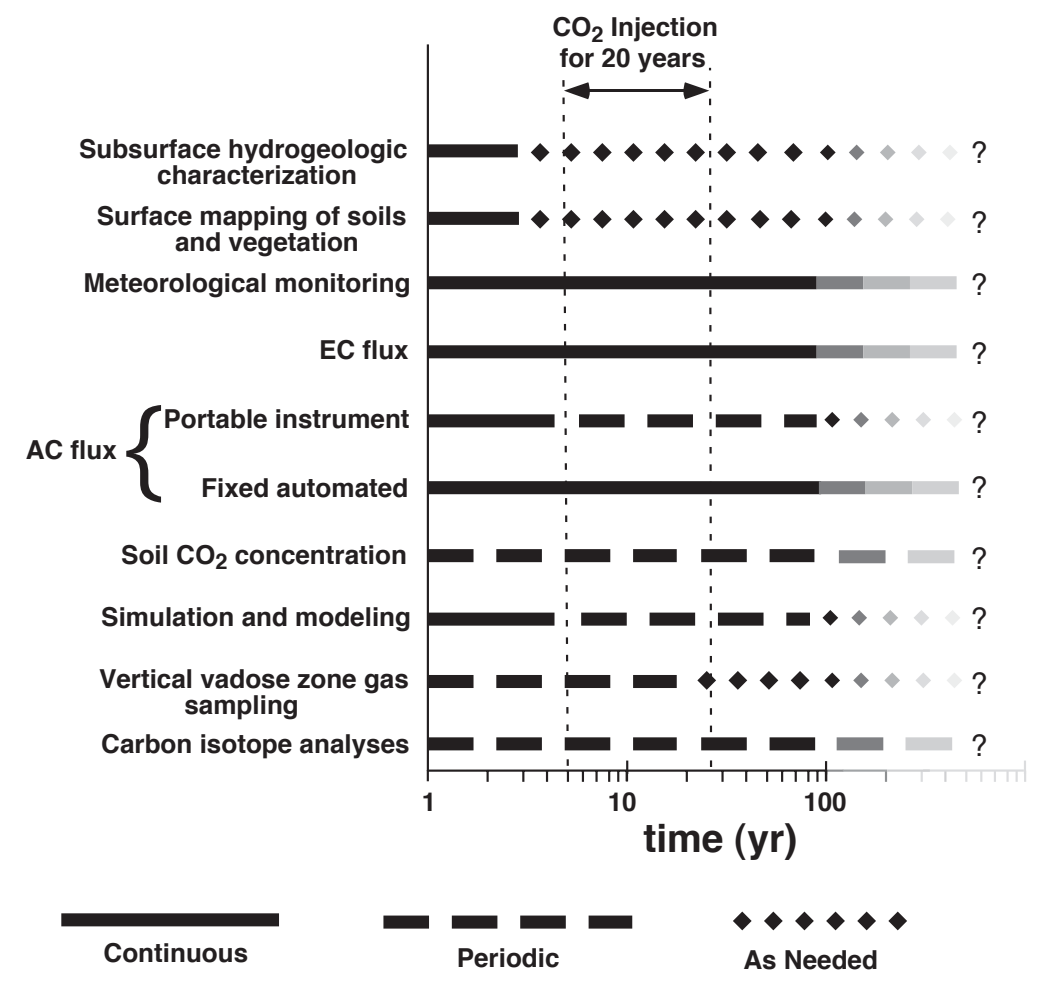

Figure 3. Example activity and schedule chart for $\mathrm{CO}_{2}$ leakage or seepage signal detection and monitoring showing generalized frequency of measurements (i.e., continuous, periodic, as needed) over time preceding, during, and following $\mathrm{CO}_{2}$ injection. Lighter shading indicates increasing uncertainty in need for activities at long times following injection. 